\title{
Research on Construction of High-quality Sports Curriculum and Forming the Culture of Soccer in Campus
}

\author{
Chen Huan ${ }^{1}$, Yang Geng ${ }^{2}$, Wu Fan ${ }^{1}$ \\ 1. Nanchang University College of Science and Technology, Jiangxi, 330029, China \\ 2.Pingxiang University, Pingxiang, Jiangxi, 337055, China
}

Keywords: ecological city; uncertainty theory; inexact fuzzy multi-objective programming (IFMOP); resource allocation

\begin{abstract}
In the reform of the continuous development today, curriculum construction, especially the construction of quality courses is always an important part of education and teaching reform. It is a starting point that embodies the modern educational thoughts, which is in line with the general principles of science, advanced nature and pedagogy. It has distinctive characteristics of the times and it can properly use modern education and teaching techniques, methods and means. The teaching effect is obviously demonstrative, the role of the radiation level of fine courses is meeting the need for higher education curriculum construction. It not only stimulates the reform and development of public physical education needs, but also satisfies the urgent need to develop cultivate high-quality talents.
\end{abstract}

\section{Introduction}

Soccer is a popular kind of ball games. It is dominated by the ball-based collective confrontation project, known as the "world's first movement", by the people's favorite. Engaged in football, players are to promote the overall quality of sports, as well as to cultivate collaboration, hard work, discipline of the team spirit. In the ordinary colleges and universities, three ball games are the most popular. Therefore, football teaching has always been the main content of college physical education. With the "National Higher Education Curriculum Guide for Physical Education" (hereinafter referred to as "Outline") issued by the ordinary colleges and universities in the football courses on the basis of the general, it has set up a special football course. In order to carry out and implement the spirit and improve the teaching quality of football special courses, it is necessary to carry out theoretical research on the framework of football special curriculum and teaching reform in colleges and universities. It is also important to establish quality courses in universities.

\section{Research object and research method}

The main purpose of this paper is to research on the domestic university sports football courses and the national sports college football curriculum quality construction as the object of study. In view of this research, professional experts and teachers are to visit the survey. The survey object is extensive and representative[1].

\section{Research objects}

This paper analyzes the relevant information of football curriculum in PE colleges and universities, and reviews the general theory, and it makes a preliminary study on all aspects of the construction of football excellent course. 


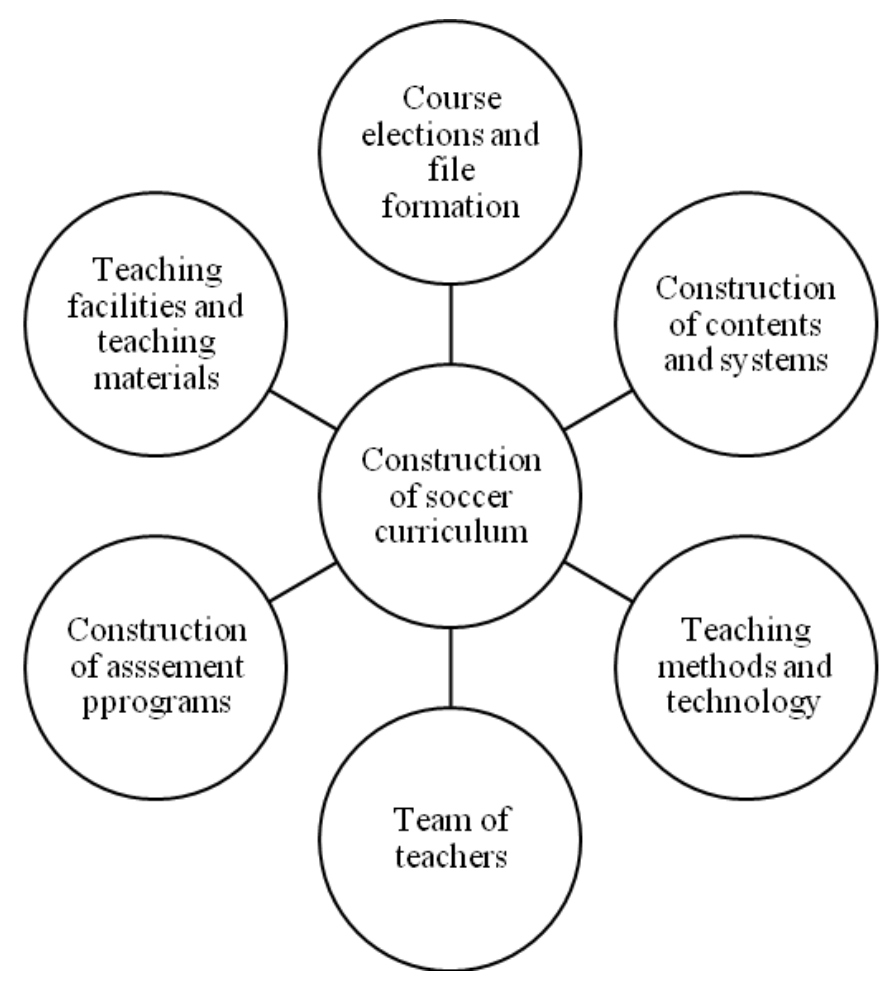

Figure 1. The basic framework of soccer course construction

\section{Research methods}

Controlling the class number to about 30 people is appropriate so that students can get more adequate counseling and teacher-student relationship becomes harmonious. In this atmosphere [2], students pay more attention to class, which makes all the anticipators of the group including the teacher establish a more positive attitude. The survey shows that the current physical education in various institutions are basically classes, that is, through a variety of ways in Figure 1 to re-divide the class. It is often a large class of the situation. Among the eight institutions surveyed, there were one of the 20 to 30 people in the soccer elective course. One of the institutions of the University of Football Election Classes to reach the number of more than 80 people, which teachers teaching organization has brought great difficulty, while the use of football venues also formed a great difficulty [3].

\section{Choices of solution}

At present, the college physical education is basically a large class form. Each lesson is a big section under normal circumstances and each student has a section of physical education every week [4]. The survey results show that the number of classes and the number of students in different institutions offered by football is also different. At the same time. Due to the various schools on the football option, classes set the number on the opening class and it has brought a great impact.

\section{Case study}

\section{Construction framework of soccer elective courses}

The course has been able to become a boutique and it is the speaker of this course that have long been committed to the results of teaching research and practice [5]. Because of this, in the excellent curriculum evaluation system, the teaching staff construction is always regarded as a primary indicator, as can be seen in Figure 2. 


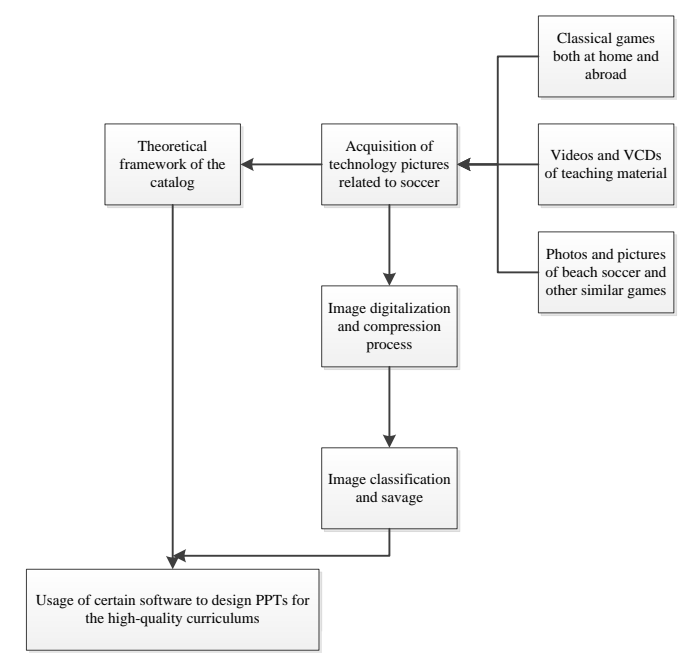

Figure 2. Construction framework of soccer elective courses

It shows that the primary task of quality courses is to build a high level of teachers, which is to ensure the sustainable development of quality courses and the need to continuously strengthen the construction of teachers [6]. At present, most of the research from the macro point of view to study the construction of teachers indicates that the quality of courses not only requires the subject to have a higher academic level, teaching level and teacher style, good morality, academic attainments, teaching ability and teaching characteristics [7], but also requires a reasonable structure of the teachers. It aims to strengthen the construction of young teachers and thus forms a reasonable plan to deploy teachers in all ages.

To recognize the academic echelon training is the top priority of the team building. We must learn from the strategic height of the importance of training young teachers, so that ahead of planning becomes comprehensive deployment [8]. Prompting them to study teaching methods and to absorb new knowledge makes them grow rapidly. We should make full use of the backbone of young teachers so as to cultivate the rapid growth of young teachers. It puts forward a lot of targeted construction measures, such as the formation of incentives with the training model, to promote young teachers to improve the quality and to improve the teacher training system to strengthen top-notch talent. Training and introduction are the direct performers of the curriculum, making the importance of the construction of the teacher's team self-evident. Most of the research is from the macro or management point of view is, in fact, the construction of fine curriculum teachers. It is an undoubtedly self-conscious and self-improvement process [9]. This paper will study the construction of teachers from the perspective of individual teachers' perspective and team building and all these are shown in Table 1.

\section{The construction of teaching content of football excellent course}

The construction of the fine course is the reform of the public basic course. Since the construction of the whole football curriculum is defined in the practice of football teaching classroom, the implementation process is also embodied in the whole course of the classroom. Because it is the construction of excellent courses at the school level, the research project comes from the reality of school reform and development. It has the clear pertinence to solve the practical problems of football teaching, and the result of the study is helpful to solve the problem of football teaching practice. The steps of the implementation directly point to the specific problems in the classroom teaching practice [10]. In the background of the reform of the school physical education curriculum, new requirements have been injected in the background of the whole educational reform. The whole process of research is the same as that of teachers and students [11]. The implementation steps of the football excellent course are designed to refer to the case study or the case study. 
Table 1 Arrangements of theoretical courses and time allocation

\begin{tabular}{|c|c|c|c|c|c|c|}
\hline Number & Basic contents & \multicolumn{3}{|c|}{ Semesters } & \multirow{2}{*}{ Total } \\
\cline { 1 - 5 } 1 & Overview of soccer game & 1 st & 2nd & 3rd & 4 th & \\
\hline 2 & Technology analysis & 4 & & & & 4 \\
\hline 3 & Strategies analysis & 4 & & & & 4 \\
\hline 4 & $\begin{array}{c}\text { Overview of soccer players body } \\
\text { exercises }\end{array}$ & & 2 & 2 & & 4 \\
\hline 5 & $\begin{array}{c}\text { Overview of soccer players } \\
\text { psychological training }\end{array}$ & & 4 & 6 & 4 & 14 \\
\hline 6 & Analysis of competitions & & & 2 & & 2 \\
\hline 7 & Principles of soccer training & & 2 & 4 & 4 & 10 \\
\hline 8 & Youth soccer training & 4 & & & & 4 \\
\hline 9 & Construction of campus team & 4 & & & & 4 \\
\hline 10 & Women's soccer & 2 & & & 2 & 4 \\
\hline
\end{tabular}

\section{Discussion of course teaching materials construction}

The first step is to establish the structure of the catalog framework according to the content of the theory class [12]. The second step can be obtained by the video recorder according to the catalog structure. Images can be from the World Cup, Special Olympics or weekly live at home and abroad. Football classic events and tactical teaching video tapes will be processed according to the directory of the image data classification and preservation [13]. It will be the theoretical directory of the framework described in the example, as shown in Figure 3.

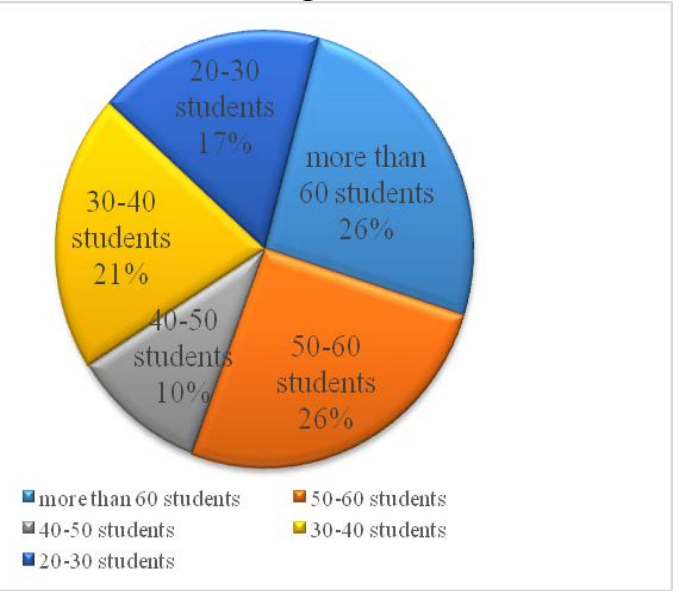

Figure 3. Percentage displayed in each section

One of the four schools in the soccer elective course was accounting for $12.5 \%$ of the surveyed schools (nearly 100 students were set for each class in the school soccer elective course). There are 3 schools in the school, accounting for $37.5 \%$ of the survey schools. There are 1 schools in 11 schools, accounting for $12.5 \%$ of the schools surveyed.

\section{Summary}

The construction of university football curriculum is based on the inheritance and development and the students' own research is the main characteristic. The classroom practice is the foothold, which is mainly based on literature, investigation and interview. The research results should help the university to deal with practical problems in soccer courses. The research shows that the construction of university football course is the practical research of theoretical guidance and support, which is the leap in the accumulation of the practice of football teaching for many years. It is the reconstruction of theory and practice. It is the process of activating theory and forming theory. It guides the practice and enhances the practice of the process. 
At the same time, from the literature review and theoretical analysis, value orientation to the content generation highlight from their own practical experience and get rich theoretical results. Throughout the study, it has basically reached some awareness and benefits.

\section{References}

[1] Yuan-yuan F W D. Model Curricula Development in Chinese Higher Education Institutions [J][J]. Tsinghua Journal of Education, 2006, 2: 019.

[2] Kirk D. Physical education, youth sport and lifelong participation: the importance of early learning experiences[J]. European Physical Education Review, 2005, 11(3): 239-255.

[3] Gui-Xia X. On Compulsory PE Course and Innovative Strategies at University in China_-Taking Hubei University as an Example[J]. IJITR, 2016, 4(1): 2673-2678.

[4] Keim M. Nation Building at Play: Sport as a tool for social integration in Post-Apartheid South Africa[M]. Meyer \& Meyer Verlag, 2003.

[5] Kahan D. Here is what interests us! Students' reconceived physical education activity offerings in an inner-city middle school[J]. Physical Educator, 2013, 70(3): 243.

[6] Blom L C, Judge L, Whitley M A, et al. Sport for development and peace: Experiences conducting US and international programs[J]. Journal of Sport Psychology in Action, 2015, 6(1): 1-16.

[7] Smolianov P, Murphy J, McMahon S G, et al. Comparing the practices of US Soccer against a global model for integrated development of mass and high-performance sport[J]. Managing Sport and Leisure, 2015, 20(1): 1-21.

[8] Nagel M S, McGee L W. Building an athletic brand: The University of South Carolina Beaufort crafts a new image[J]. Case Studies in Sport Management, 2012, 1(1): 59-75.

[9] Curtner-Smith M, Sofo S. Preservice teachers' conceptions of teaching within sport education and multi-activity units[J]. Sport, Education and Society, 2004, 9(3): 347-377.

[10]Martínez-Alemán A M, Wartman K L. Online social networking on campus: Understanding what matters in student culture[M]. Routledge, 2008.

[11]Nash M. Using the idea of 'communities of practice'and TGfU to develop physical education pedagogy among primary generalist pre-service teachers[J]. Asian Journal of Exercise and Sports Science, 2009, 6(1): 15-21.

[12]Demerath P. Producing success: The culture of personal advancement in an American high school[M]. University of Chicago Press, 2009.

[13]Chen A. The impact of social change on inner-city high school physical education: An analysis of a teacher's experiential account[J]. Journal of Teaching in Physical Education, 1999, 18(3): 312-335. 